\title{
Erratum to: Determination of cocaine and metabolites in hair by column-switching LC-MS-MS analysis
}

\author{
Marcela Nogueira Rabelo Alves • Gabriele Zanchetti • \\ Alberto Piccinotti · Silvia Tameni • \\ Bruno Spinosa De Martinis • Aldo Polettini
}

Published online: 13 July 2013

(C) Springer-Verlag Berlin Heidelberg 2013

Erratum to: Anal Bioanal Chem

DOI: 10.1007/s00216-013-7046-3

The authors should like to call your attention to the fact that unfortunately the following acknowledgment was mistakenly omitted in the published article:

"The main author (Marcela Nogueira Rabelo Alves) was financially supported by a CNPq's scholarship (201968/2012-6)."

The online version of the original article can be found at http://dx.doi.org/10. 1007/s00216-013-7046-3.

M. N. R. Alves

Faculdade de Ciências Farmacêuticas de Ribeirão Preto,

Universidade de São Paulo, Av. do Café,

Ribeirão Preto 14040-903, São Paulo, Brazil

G. Zanchetti $\cdot$ A. Piccinotti $\cdot$ S. Tameni

Synlab Italia Srl, Via Orzinuovi,

111-25125 Brescia, Italy

B. S. De Martinis

Departamento de Química, Faculdade de Filosofia Ciências e

Letras de Ribeirão Preto, Universidade de São Paulo,

Av. Bandeirantes, 3900, Ribeirão Preto 14040-901,

São Paulo, Brazil

A. Polettini $(\bowtie)$

Department of Public Health and Community Medicine,

University of Verona, P.le Scuro 10, 37134 Verona, Italy

e-mail: aldo.polettini@univr.it 